\title{
Influence of Lignocellulosic Waste Pre-Treatment on the Characteristics of Bond Rupture
}

\author{
Štěpán Hýsek *®D, Jaroslav Čermák and Martin Lexa \\ Department of Wood Processing and Biomaterials, Faculty of Forestry and Wood Sciences, \\ Czech University of Life Sciences in Prague, Praha 16521, Czech Republic \\ * Correspondence: hyseks@fld.czu.cz
}

Received: 5 August 2019; Accepted: 25 August 2019; Published: 2 September 2019

\begin{abstract}
Post-harvest crop residues are an interesting raw material for the production of composite materials. However, their surface often contains waxy and siliceous substances, which can cause adhesion problems. Therefore, various surface pre-treatment methods have been developed to increase the surface tension of these particles and hence to improve adhesive adhesion. The influence of hydrothermal, chemical, plasma and enzymatic treatment was investigated. The aim of the paper is to evaluate the effect of pre-treatments of post-harvest crop residues on the nature of joint failure and adhesive dispersion on the particles. The evaluation is based on microscopic analysis of particles obtained from the rupture area after internal bonding tests. The nature of bond failure and adhesive dispersion on the particle surface is evaluated. The results show a clear influence of material pre-treatment on the failure bond of the bond and, to a large extent, correlate with the mechanical properties of composites published in previous studies. The most suitable treatment appears to be a plasma treatment at a properly adjusted intensity. Conversely, the unsuitable treatment was alkaline, which, although it increased adhesion, deteriorated the overall mechanical properties. Hydrothermal treatment could be also considered as an industrially suitable method.
\end{abstract}

Keywords: waste; straw; composites; pre-treatment; adhesive; rapeseed; wheat

\section{Introduction}

Composites made of natural materials have many advantages over composites based on glass, carbon, polypropylene and other synthetic fibers. Composites made of natural materials have excellent specific mechanical properties, are made from a renewable source, tool wear during cutting is lower and they absorb energy, vibration and ultraviolet radiation excellently [1]. However, these materials also have disadvantages and are therefore the subject of extensive research where their properties are optimized, and combinations of properties are sought for a given use [2].

In a study describing hemp straw composites, hemp straw and wheat stem adhesive were used to produce biocomposites. The minimum amount needed to ensure good cohesion was $15-20 \%$ of wheat straw in the dry mix (and $80-85 \%$ hemp). The soluble components of wheat straw after hydrothermal treatment ensured the adhesive ability. The mechanical properties were sufficient despite the relatively low density ranging from 165 to $190 \mathrm{~kg} / \mathrm{m}^{3}$ [3]. Another work investigated the properties of manufactured straw-based fiberboards without resin at various hot pressing temperatures. Fibreboard without synthetic adhesive was prepared by pressing at $160-200^{\circ} \mathrm{C}$. The results revealed that proteins and lignin released at elevated temperature and pressure were beneficial in forming new covalent bonds and showed better performance at higher temperatures. Therefore, it showed that a thermal extract from wheat straw can be used as an adhesive. However, at a pressing temperature of more than $190^{\circ} \mathrm{C}$, the colour of the boards darkened, and energy consumption was excessive. No significant changes occurred up to $190^{\circ} \mathrm{C}$ [4]. 
The disadvantage of natural fibers is the high variability of their properties. Research was carried out to focus on high variability in fiber size and their mechanical properties for flax fibers. Two types of flax collected from two different growing sites were used for the measurement. It was investigated whether a correlation exists between the tensile strength of samples with the same stem diameter range, Young's modulus, failure strain, fiber diameter and various types of flax or the growth site. No statistically significant correlations were found. The results showed that samples that differed in stem diameter had a statistically significant positive correlation with fiber diameter and negative correlation with tensile strength [5]. In the work seeking flax and hemp applications, samples of non-woven fabrics of flax and hemp mixed with polypropylene fibers were exposed to three environments differing in water and fungus presence for 28 days. In the first environment no fungi and no water were present, in the second one only water was present, and in the third one both water and Chaetomium globosum fungus were present. Weight loss over time was measured and the mechanical properties of composite samples in various configurations were tested. The results showed that mould growth significantly influenced the weight loss of dry matter (about $15 \%$ for $100 \%$ hemp and $30 \%$ for $100 \%$ flax mat) and a decrease in tensile modulus of the tested natural fiber non-wovens and composites (about $33 \%$ for hemp-based composites and $43 \%$ for flax-based composites). The effect depended both on the type and length of the fibers and on the exposure and time conditions [6]. Biocomposites can also be produced by technology that mixes dry corn starch with hemp pulp and then the dry mixture is treated with water at $100^{\circ} \mathrm{C}$. The results showed that the ideal amount of starch, regardless of the pulp fraction, is $10 \%$. At $10 \%$ deformation, the compressive stress is in the range of 2.4-3.0 MPa, flexural strength 4.4-6.3 MPa and tensile strength 0.23-0.45 MPa. The microstructural analysis further showed that $10 \%$ of the starch constitutes a sufficient number of contact zones that strengthen the final product. The application of $20-50 \%$ corn starch does not affect the later properties of the biocomposite [7].

A frequent phenomenon in the manufacture of composites from natural materials is the lack of adhesion between the material and the adhesive due to the low surface energy of the natural fibers and particles. Low surface energy is caused by the presence of waxy substances, which must be removed in order to increase the surface energy of the bonded material and achieve better adhesion with the adhesive [8]. Various methods of material pre-treatment have been developed for this purpose $[9,10]$. It was shown that through increase of particle surface energy some of the pre-treatments improve the bonding between particle and surface. However the final mechanical properties (internal bonding or bending strength) depend not only on the surface energy of treated particles. For example, alkaline treatment increased the surface energy of treated particles and improved substantially the adhesion $[8,11,12]$, however it was too aggressive, and celluloses in the treated material degraded and the final mechanical properties decreased.

Scanning electron microscopy (SEM) is a useful method for evaluation of morphology and bonding failure. Klímek a kol. (2016) [13] observed using SEM the interface between particle and adhesive and evaluated adhesive dispersion on particles and the character of the bond rupture. Other authors used also other method for the evaluation of the interface between particle and adhesive. A goniometer was used for evaluation of the contact angle between particle surface and liquids [14,15].

Based on the literature search and our previous work it can be stated that some treatment methods influence surface energy of treated particles and consequently the adhesion and particleboard properties. The properties of the produced particle boards have already been published in our earlier work $[8,11,12,16,17]$. We are hypothesing that all conducted treatments effected morphology of treated particles on microscopic level and adhesive dispersion on the particle surface. The aim of the presented research is to evaluate the effect of pre-treatments as an intermediate step in the production of particle boards from post-harvest crop residues on the nature of joint failure and adhesive dispersion on the particles. This article further summarizes the comprehensive results from previous research and observes the developed materials from the microstructure perspective. 


\section{Materials and Methods}

\subsection{Materials}

Particle boards of winter rape straw, winter wheat straw and winter wheat husks bonded with epoxy-polyester adhesive and urea-formaldehyde (UF) adhesive were used for the research. The combination of the individual pre-treatments and adhesives is shown in Table 1. Table 1 also lists the source, which details the production methodology of the relevant composites.

Table 1. The combination of the individual pre-treatments and adhesives.

\begin{tabular}{|c|c|c|c|c|}
\hline Type of Particles & Pre-Treatment & Adhesive Used & $\begin{array}{c}\text { Internal } \\
\text { Bonding (kPa) }\end{array}$ & References \\
\hline \multirow{3}{*}{ Rapeseed straw } & Untreated & epoxy-polyester & 429 & \multirow{3}{*}[8,12]{} \\
\hline & Hydrothermal treatment & epoxy-polyester & 505 & \\
\hline & Chemical treatment & epoxy-polyester & 340 & \\
\hline \multirow{4}{*}{ Wheat straw } & Untreated & urea-formaldehyde & 61 & \multirow{4}{*}[16]{} \\
\hline & Enzymatic (pectinases) & urea-formaldehyde & 96 & \\
\hline & $\begin{array}{c}\text { Enzymatic (pectinases }+ \\
\text { xylanases) }\end{array}$ & urea-formaldehyde & 95 & \\
\hline & Enzymatic (xylanases) & urea-formaldehyde & 78 & \\
\hline \multirow{4}{*}{ Rapeseed straw } & Untreated & urea-formaldehyde & 93 & \multirow{4}{*}{ [16] } \\
\hline & Enzymatic (pectinases) & urea-formaldehyde & 74 & \\
\hline & $\begin{array}{c}\text { Enzymatic (pectinases }+ \\
\text { xylanases) }\end{array}$ & urea-formaldehyde & 99 & \\
\hline & Enzymatic (xylanases) & urea-formaldehyde & 91 & \\
\hline \multirow{3}{*}{ Wheat straw } & Untreated & urea-formaldehyde & 37 & \multirow{3}{*}[17]{} \\
\hline & $\begin{array}{c}\text { Plasma treatment (lower } \\
\text { power) }\end{array}$ & urea-formaldehyde & 59 & \\
\hline & $\begin{array}{l}\text { Plasma treatment (higher } \\
\text { power) }\end{array}$ & urea-formaldehyde & 61 & \\
\hline \multirow{4}{*}{ Wheat husks } & Untreated & urea-formaldehyde & 12 & \multirow{4}{*}[11]{} \\
\hline & Hydrothermal treatment & urea-formaldehyde & 29 & \\
\hline & Chemical treatment & urea-formaldehyde & 8 & \\
\hline & Plasma treatment & urea-formaldehyde & 23 & \\
\hline
\end{tabular}

\subsection{Methods}

The nature of joint failure and adhesive dispersion on the particle surface were evaluated using scanning electron microscopy. For electron microscopy, particles were removed from specimens damaged after the tensile strength test perpendicular to the level of the board. The collected particles were gold-coated using a laboratory coater Q150R ES (Quorum Technologies Ltd) and microscopic analysis was carried out using scanning electron microscope MIRA 3 (Tescan Orsay Holding, a.s.). A secondary electron detector was used, the acceleration voltage was $15 \mathrm{kV}$, the working distance was $9 \mathrm{~mm}$ and the spot size was $8 \mathrm{~nm}$. The vacuum modes were: gun pressure: $1.2 \times 10^{-8} \mathrm{~Pa}$, column pressure: $6.7 \times 10^{-4} \mathrm{~Pa}$, chamber pressure $7.9 \times 10^{-2} \mathrm{~Pa}$. 


\section{Results and Discussion}

\subsection{Composites from Rapeseed Straw Bonded with Epoxy-Polyester Resin}

\subsubsection{Untreated Particles}

In contrast to wheat particles, untreated rapeseed particles show relatively good spillage of adhesive over the surface of the material (Figure 1a), which may be due to the higher surface tension of the rapeseed stem surface. The poor adhesion of the adhesive to the surface can be seen in Figure $1 \mathrm{~b}$-failure in the bonded joint (smooth clean impression in the adhesive). However, it is exceptionally possible to observe a disturbed structure of rapeseed tissues (Figure 1a).

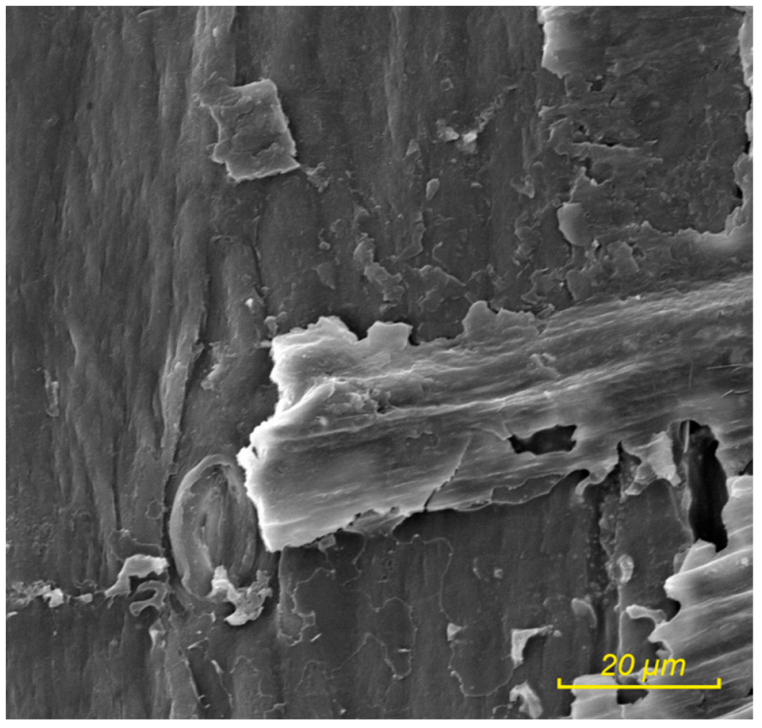

(a)

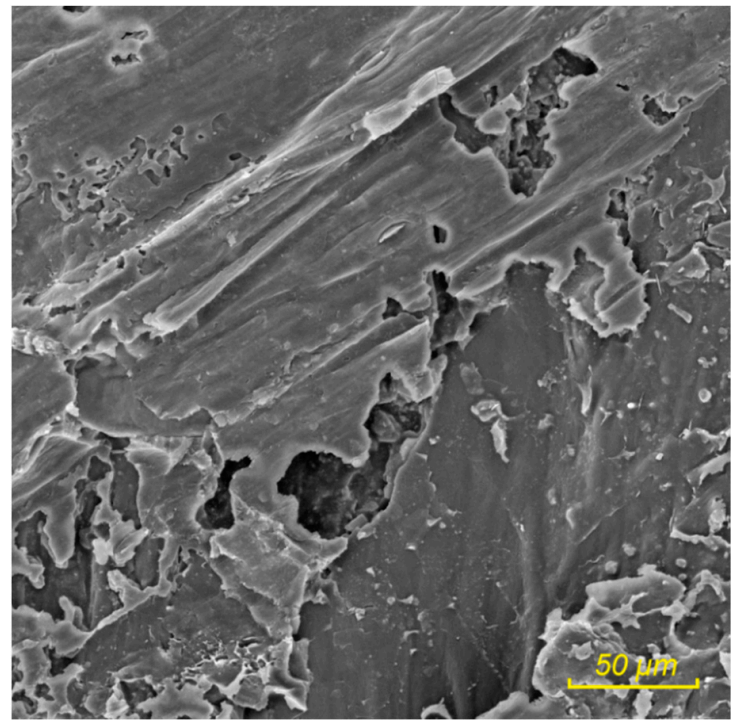

(b)

Figure 1. Particle board from rapeseed straw bonded with epoxy-polyester adhesive, untreated particles; (a) thorough spill of adhesive on the surface of the particles, (b) adhesion error.

\subsubsection{Hydrothermally Treated Particles}

Leaching in boiling water improves adhesion due to the partial removal of waxy substances from the particle surface [9]. The failure of the joint occurs at the adhesive and material interface (Figure 2a), but the cohesive failure in the material itself is also evident (Figure $2 b$ ). The surface treatment provided greater strength of the bonded joint and hence the failure of the particle material also occurred [12].

\subsubsection{Chemically Treated Particles}

The effect of the alkaline treatment is evident at any magnification. Surface erosion and irregularities can be observed (Figure 3a). The adhesion is improved because of removal of the protective wax layer in combination with surface roughening [9]. The failure occurs both in the adhesive and in the bonded joint (to a small extent), as well as in the adherend (Figure 3b). Moreover, the failure is not areal as in the previous cases, but rather spatial. The presence of residual Ca crystals (marked by arrows) in the structure of the exposed mesh also has a significant but unknown effect [9]. Overall, after evaluating the observations of all variants, the bonding quality after alkaline treatment using epoxy polyester adhesive is the best. However, the strength of the particle boards produced was not the highest due to the disruption of the particle structure via this aggressive treatment [18]. 


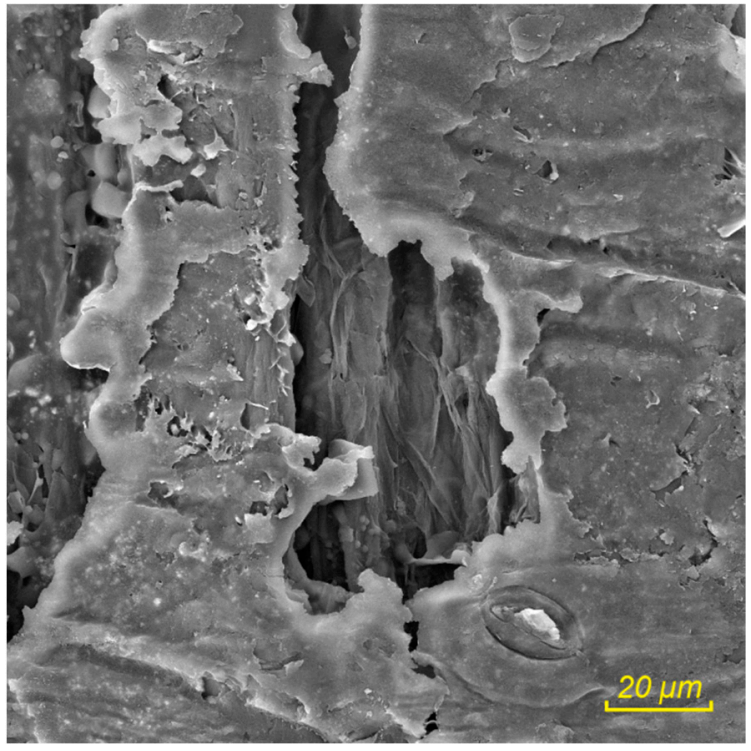

(a)

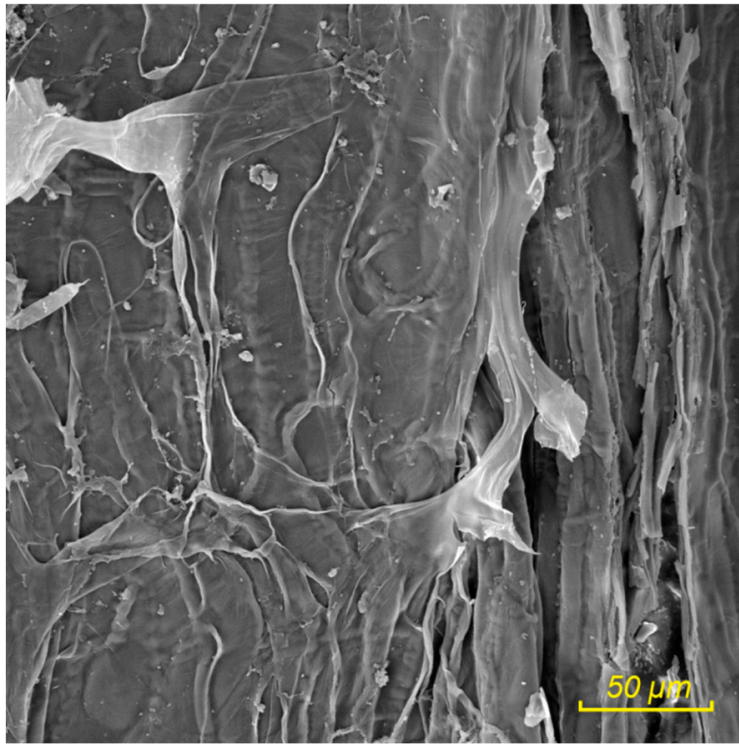

(b)

Figure 2. Particle board from rapeseed straw bonded with epoxy-polyester adhesive, hydrothermally treated particles; (a) adhesion failure, (b) cohesive failure in the material

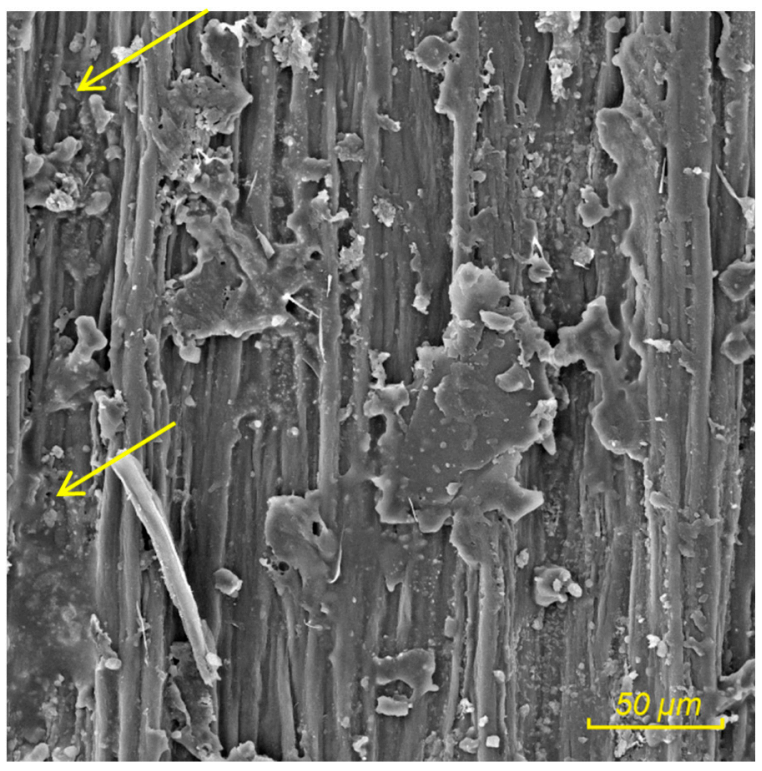

(a)

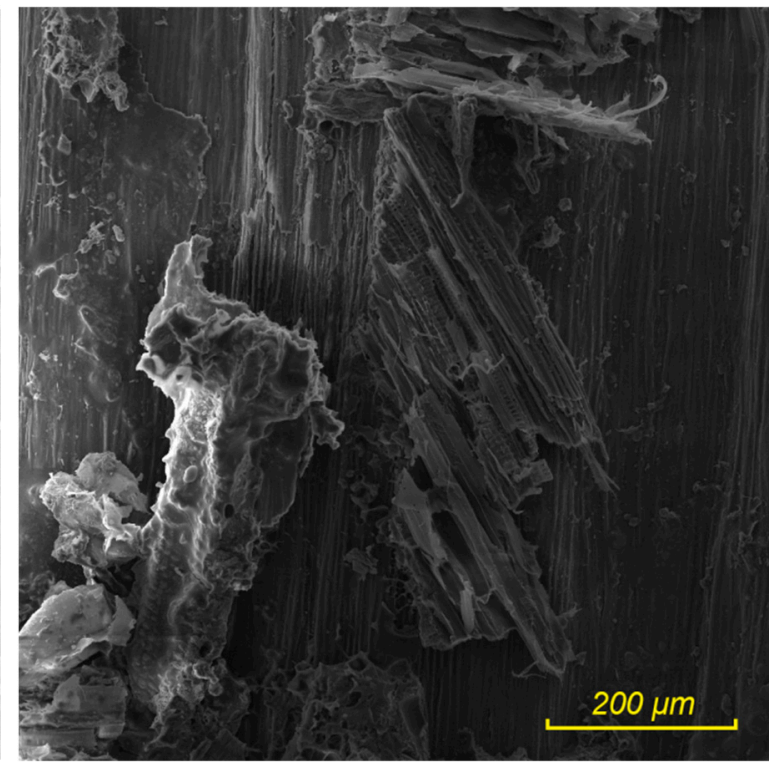

(b)

Figure 3. Particle board from rapeseed straw bonded with epoxy-polyester adhesive, chemically treated particles; (a) irregularities on the surface of the particles, (b) cohesive failure in the material.

\subsection{Composites from Enzymatically Treated Straw Bonded with Urea-Formaldehyde Adhesive (UF) Resin}

\subsubsection{Untreated Wheat Particles}

Enzymatically untreated samples contain large, extensive layers of adhesive with a counterpart impression and, conversely, intact surfaces apparently unaffected by the adhesive. This suggests a very poor adhesion of the adhesive to untreated wheat particles. While very small but numerous adhesive fragments are often seen in other pre-treatment methods, only clean areas (Figure 4a) or stronger adhesive layers peeled off from the counterpart remain in these samples (Figure 4b). 


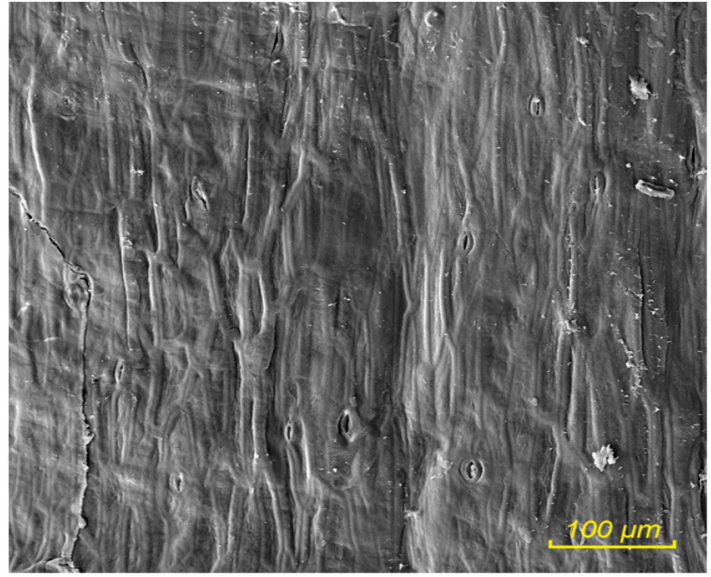

(a)

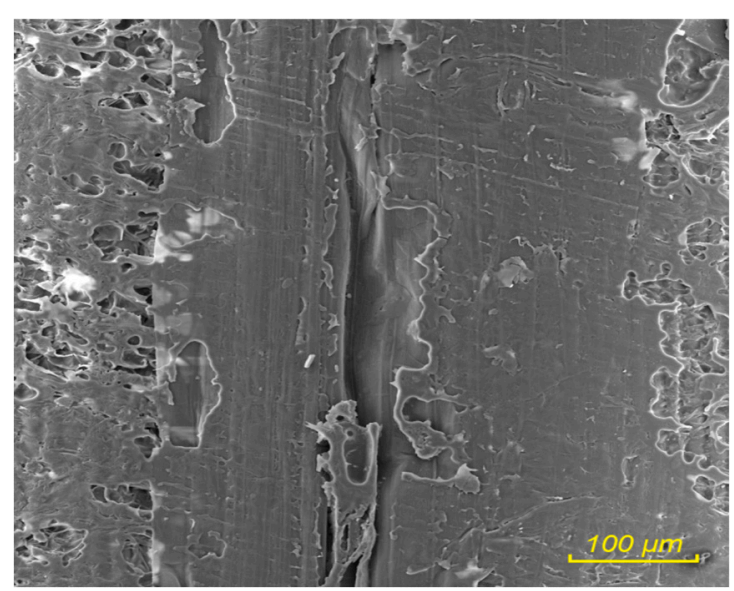

(b)

Figure 4. Particle board made of wheat straw bonded with urea-formaldehyde adhesive (UF) adhesive, untreated wheat particles; (a) adhesion error-particle, (b) adhesion error-adhesive.

\subsubsection{Wheat Particles Treated with Pectinases}

After an enzymatic treatment with pectinases, wetting of the surface is slightly better. However, the failure still occurs only in the form of peeling at the adhesive-adherend interface (Figure 5). Adherend damage indicating structure breakdown caused by tearing of bonded joint did not occur in the selected samples.

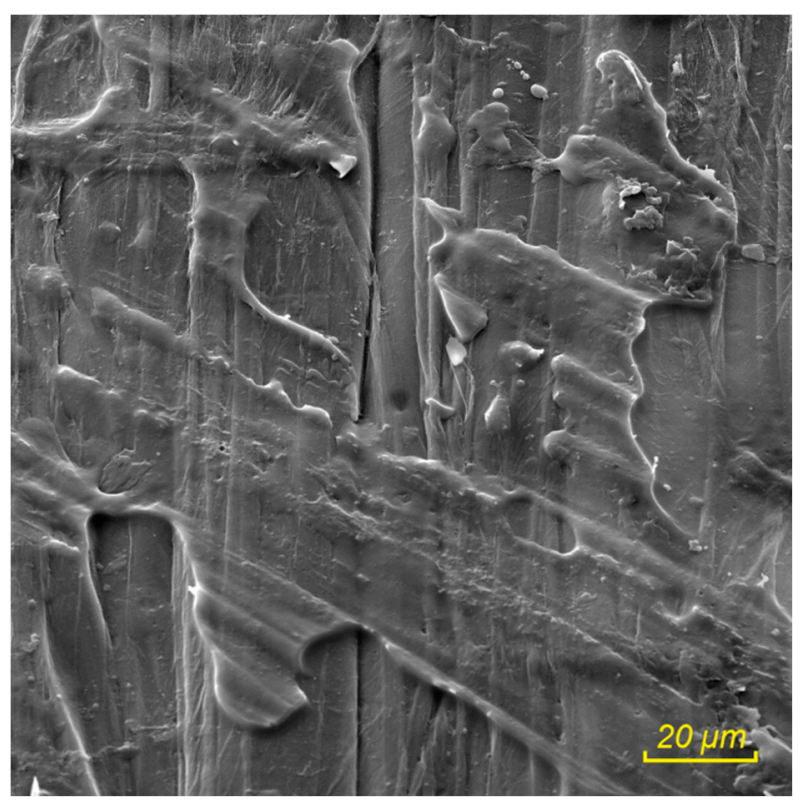

Figure 5. Particle board made of wheat straw bonded with UF adhesive, enzymatically (pectinases) treated wheat particles; adhesion error.

\subsubsection{Wheat Particles Treated with a Combination of Pectinases and Xylanases}

In this case both cohesive and adhesion errors occurred. Numerous and extensive damage to the surface of the material and the adhesive are visible on the examined fragment (Figure 6a). In this case, the adhesive consisted of massive surface layers. It is interesting to note the unknown cause (for now) of semi-circular imprints in these droplets (Figure 6b). 


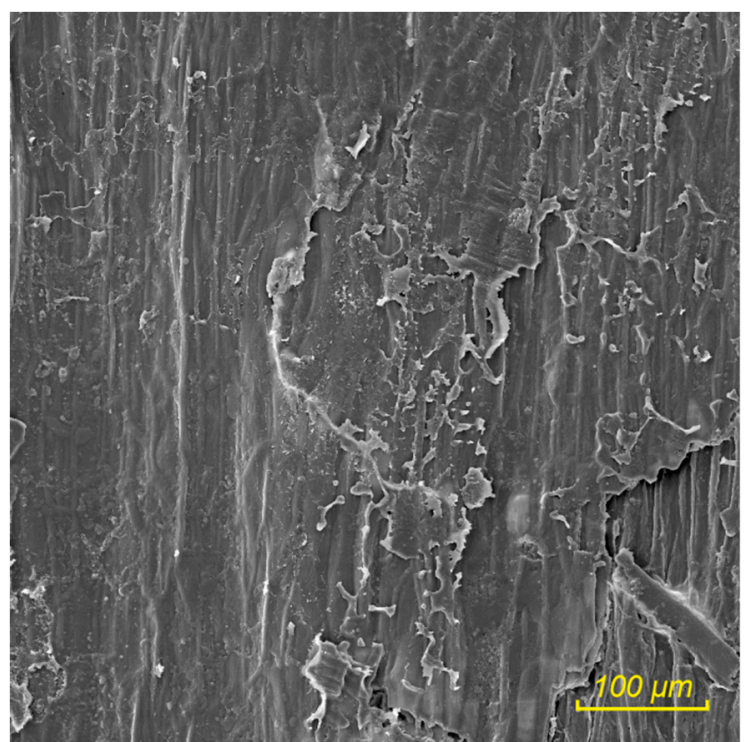

(a)

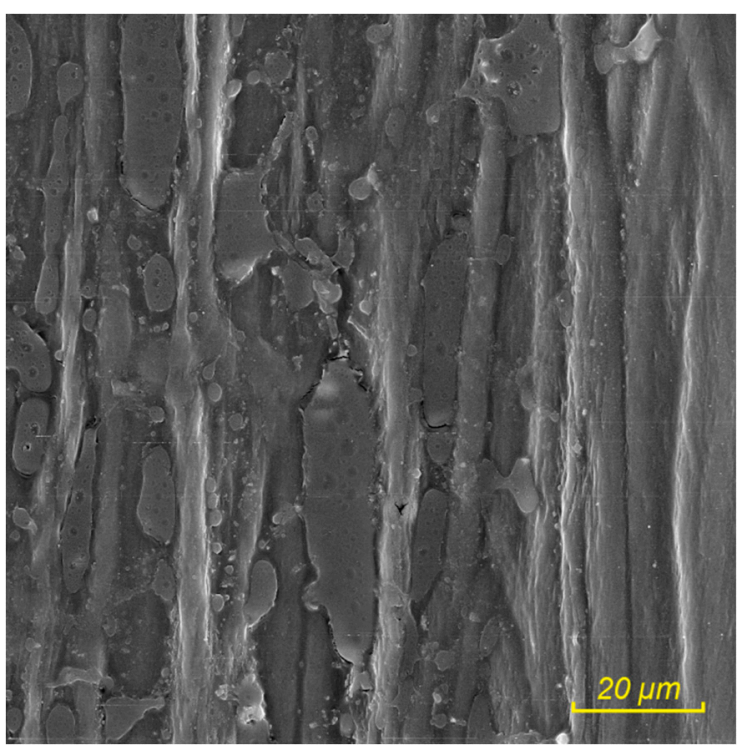

(b)

Figure 6. Particle board made of wheat straw bonded with UF adhesive, enzymatically treated (combination) wheat particles; (a) mixed character of joint failure, (b) bubbles in the adhesive.

\subsubsection{Wheat Particles Treated with Xylanases}

Given that damage is only evident on the phase boundary (Figure 7) on the vast majority of the examined surface, it is clear that despite the very good dispersion, the adhesion of the adhesive to the foundation is not good. The enzymatic treatment of this step, therefore, does not create ideal conditions for the formation of solid joints.

Particleboards from wheat straw treated by enzymes achieved higher internal bonding values than particleboards from plasma-treated wheat straw. The difference between the two treatments can be caused by dry vs. wet conditions. The dry method of plasma treatment did not ensure additional washing of the surface from dust [16,17].

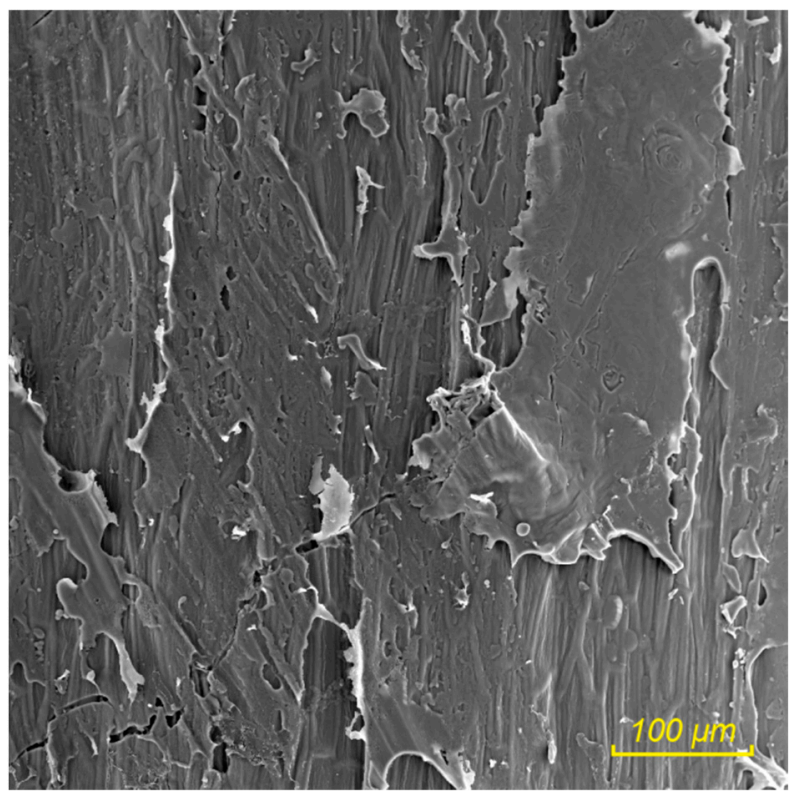

Figure 7. Particle board made of wheat straw bonded with UF adhesive, enzymatically treated (xylanases) wheat particles; adhesion failure. 


\subsubsection{Untreated Rapeseed Particles}

In accordance with the surface tension values of untreated rapeseed particles, a good dispersion of adhesive (Figure 8a) is evident in the untreated material [16]. The adhesive spills very well into the unevenness of the material and, in comparison with wheat samples, does not create "drops", i.e. it wets the surface better. This corresponds to a higher surface tension on the rapeseed particles. However, the failure occurs exclusively at the phase interface (Figure 8b). If it occurs, damage to the particle material is also exceptional in the pith area.

The achieved internal bonding values are significantly lower than the internal bonding values of the particleboards from rapeseed straw in [12], but this difference caused by the different adhesive, density and vertical density profile of boards.

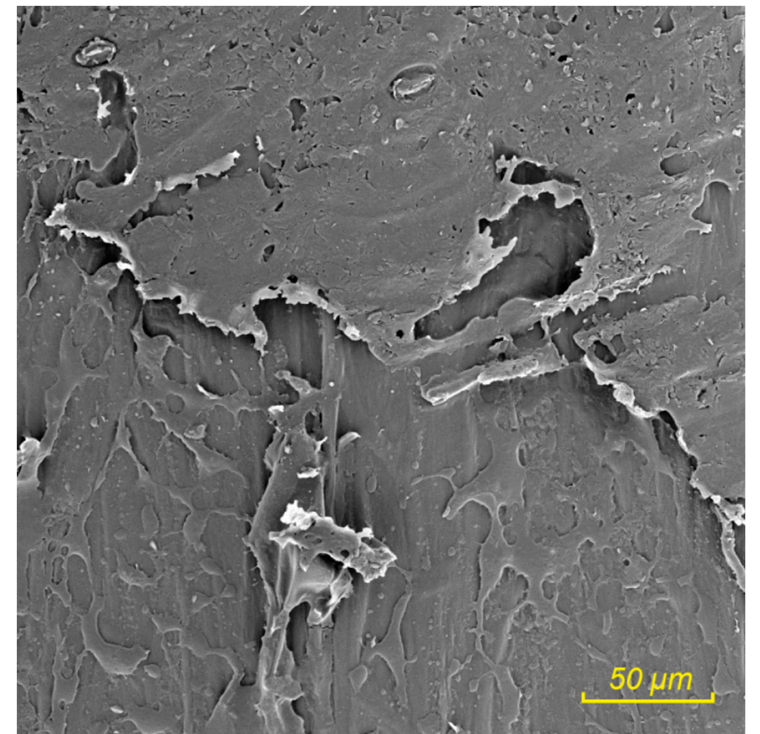

(a)

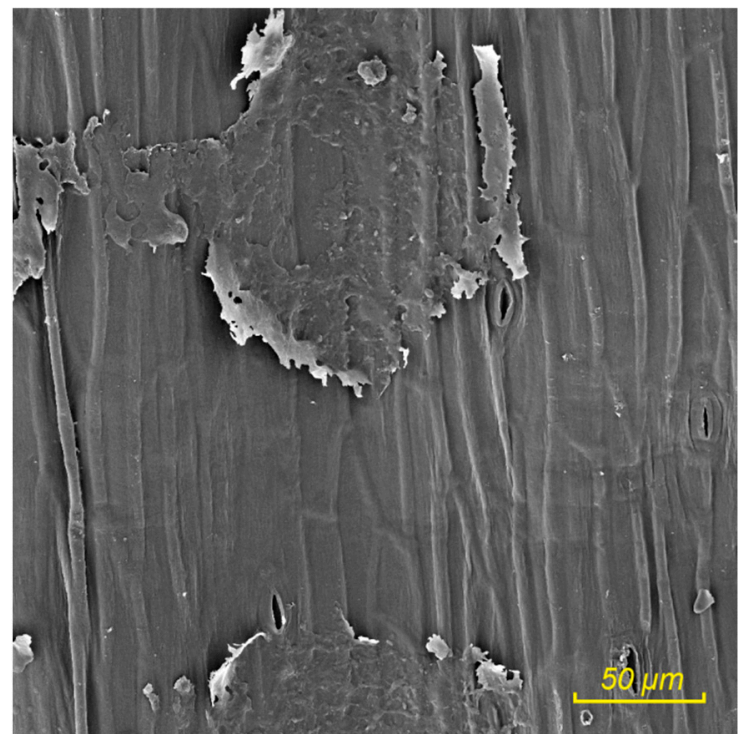

(b)

Figure 8. Particle board from rapeseed straw bonded with UF adhesive, enzymatically untreated rapeseed particles; (a) application of adhesive over a large surface, (b) adhesion failure.

\subsubsection{Rapeseed Particles Treated with Pectinases}

The sample surface is relatively clean, with only torn adhesive fragments occurring locally (Figure 9a). The damaged structure of the material did not occur. As with the wheat samples, semi-circular depressions occur in drops of adhesive without a known cause (Figure 9b).

\subsubsection{Rapeseed Particles Treated with a Combination of Pectinases and Xylanases}

The bonding results after this treatment are very good. The adhesive has good wettability and surface adhesion. After breakage, there is a failure at all three levels (Figure 10a). Of course, there was also a failure in the particle in the pith area (Figure 10b). Hýsková et al. 2019 [16] describes massive surface erosion via this combination of the enzymes. However, better adhesive adhesion did not result in higher strength of the produced composites. 


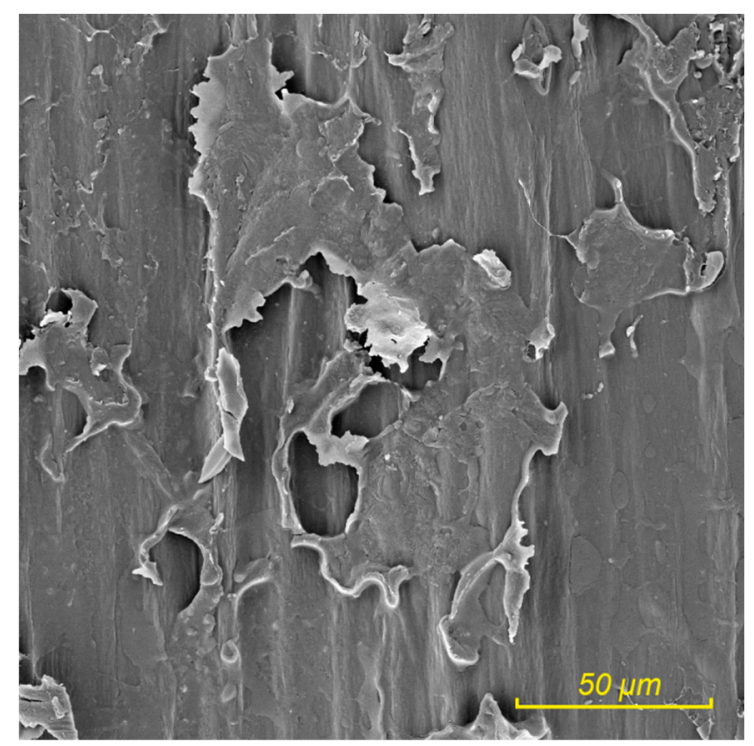

(a)

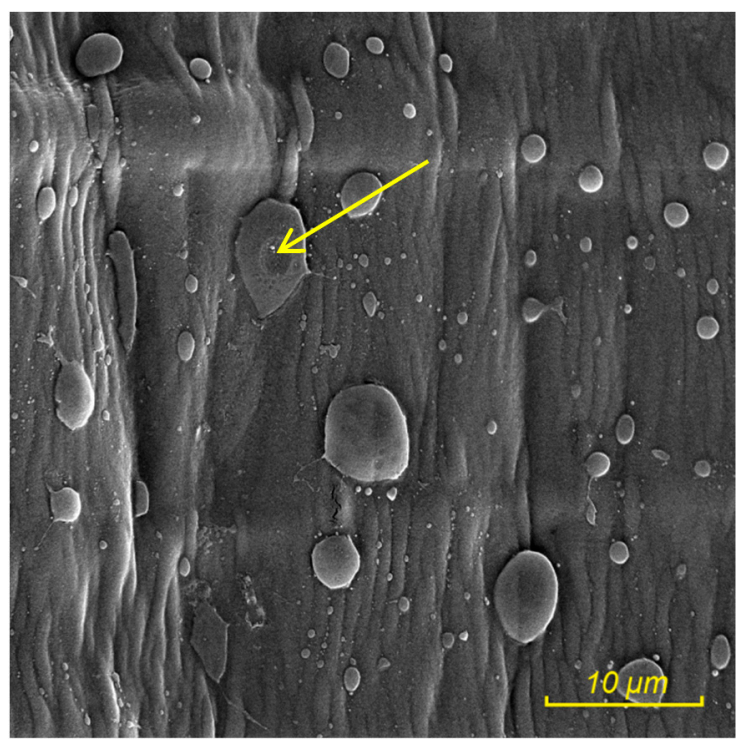

(b)

Figure 9. Particle board from rapeseed straw bonded with UF adhesive, enzymatically treated (xylanases) rapeseed particles; (a) adhesion error, (b) bubbles in the adhesive.

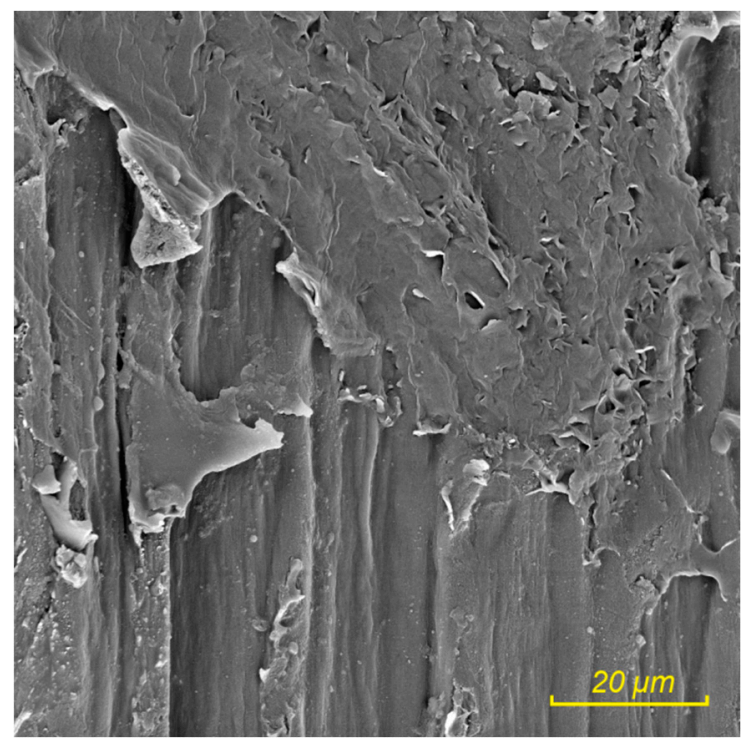

(a)

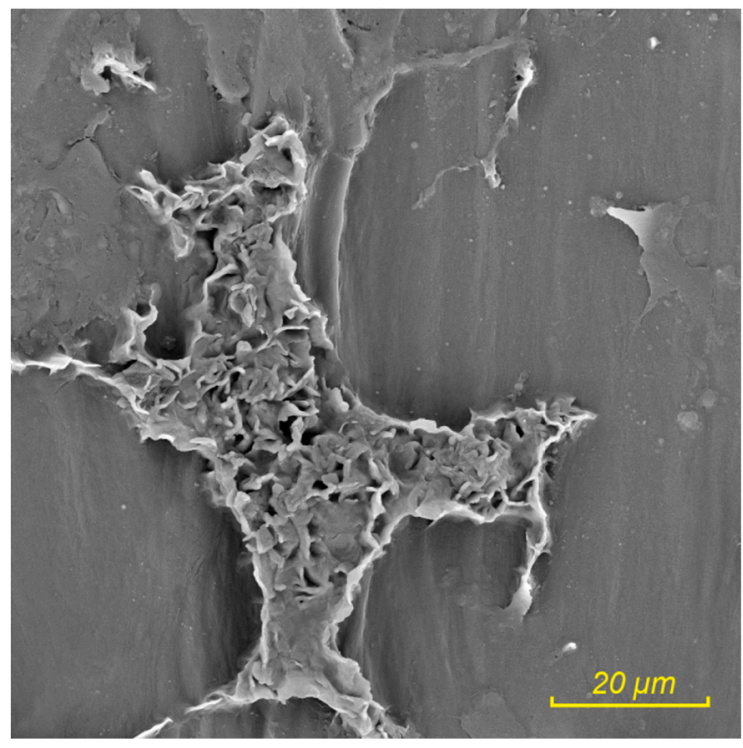

(b)

Figure 10. Particle board from rapeseed straw bonded with UF adhesive, enzymatically treated (combination) rapeseed particles; (a) adhesion and cohesion error, (b) failure in the pith of the particles.

\subsubsection{Rapeseed Particles Treated with Xylanases}

The adhesive creates either droplets on the surface or a thicker skin layer in the case of a local, larger amount of adhesive. After breakage, we can observe the combined damage of the joint at the material interface and in the adhesive. Adhesive surfaces show smooth surfaces created under peeling of the material counterpart, as well as torn edges (Figure 11). In this case, this is a frequent and regular phenomenon, which indicates that under tensile stress, in this case the bond is once again the weakest component. 


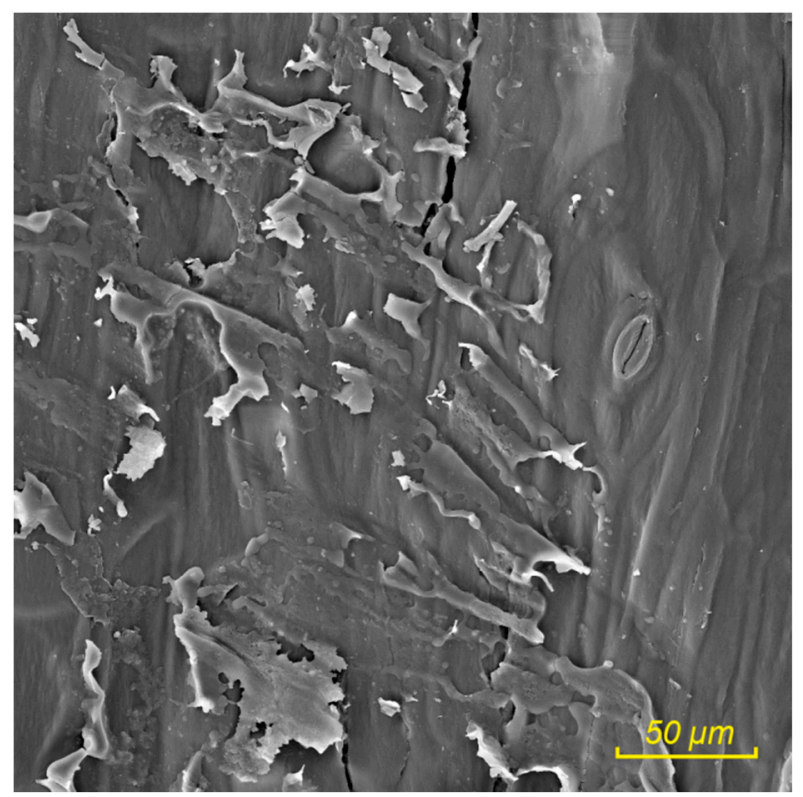

Figure 11. Particle board from rapeseed straw bonded with UF adhesive, enzymatically treated (xylanases) rapeseed particles; adhesion error.

\subsection{Composites from Plasma-Treated Straw Bonded with UF Resin}

\subsubsection{Untreated Wheat Particles}

As previously shown, the untreated surface of the wheat particles exhibited the worst adhesion of all of the studied variants. The insufficient properties of straw-based boards glued by UF adhesive were also reported by [10]. Looking at a larger area, only smaller adhesive fragments are visible (Figure 12). Quite often, small objects are trapped in the adhesive, as likely impurities in the form of dust particles. The surfaces of the investigated particles were relatively undamaged, with only small adhesive residues.

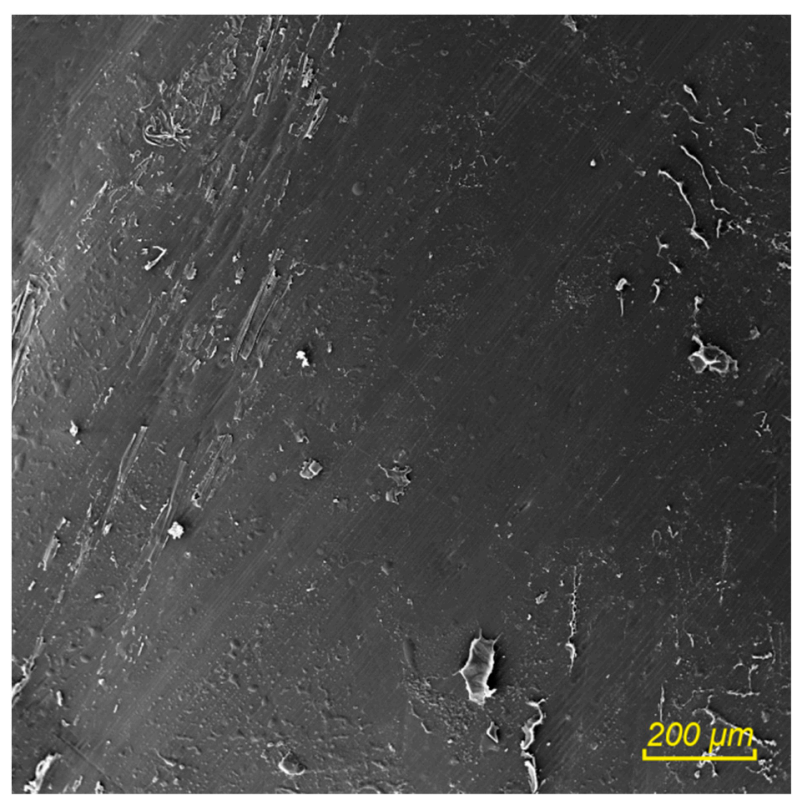

Figure 12. Particle board from wheat straw bonded with UF adhesive, plasma untreated particles; adhesion error. 


\subsubsection{Particles Treated with a Lower Degree of Plasma Treatment}

Compared to the reference sample, this variant at first glance shows a very strong bond between the adhesive and the surface structure. The adhesive creates large plastic layers with very good wettability. The structure of the material was largely damaged, and its fractions were captured in the adhesive (Figure 13a). Based on observations, this treatment can be described as promising. As this is a dry treatment method, there is again an increased incidence of dust particles in the adhesive (Figure 13b). Particle boards made of such treated particles achieved the highest internal bonding and also the lowest thickness swelling [17]. The results corresponds with Klímek et al. (2016) [13], where the plasma treatment substantially enhanced the resin distribution on polyethylene terephthalate flakes.

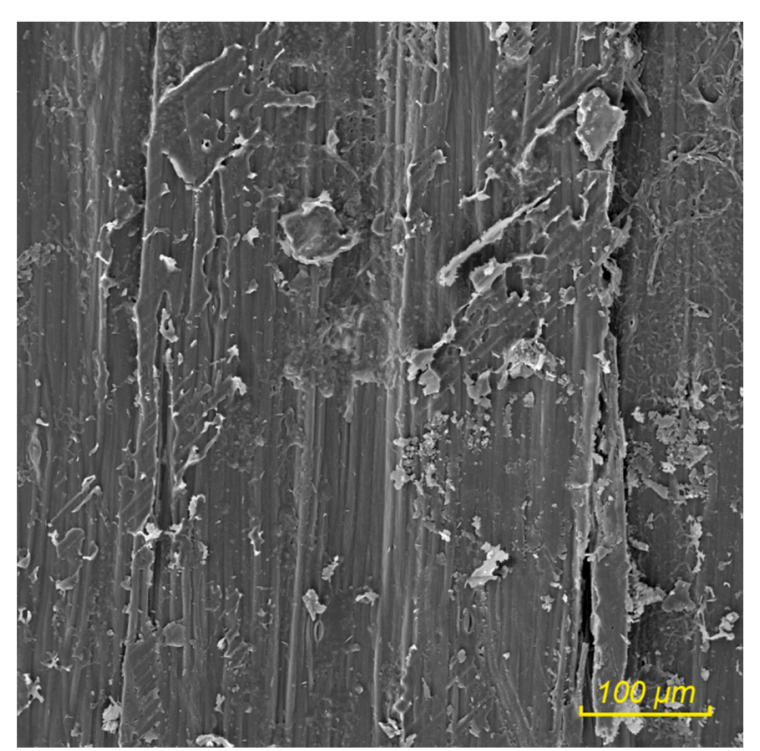

(a)

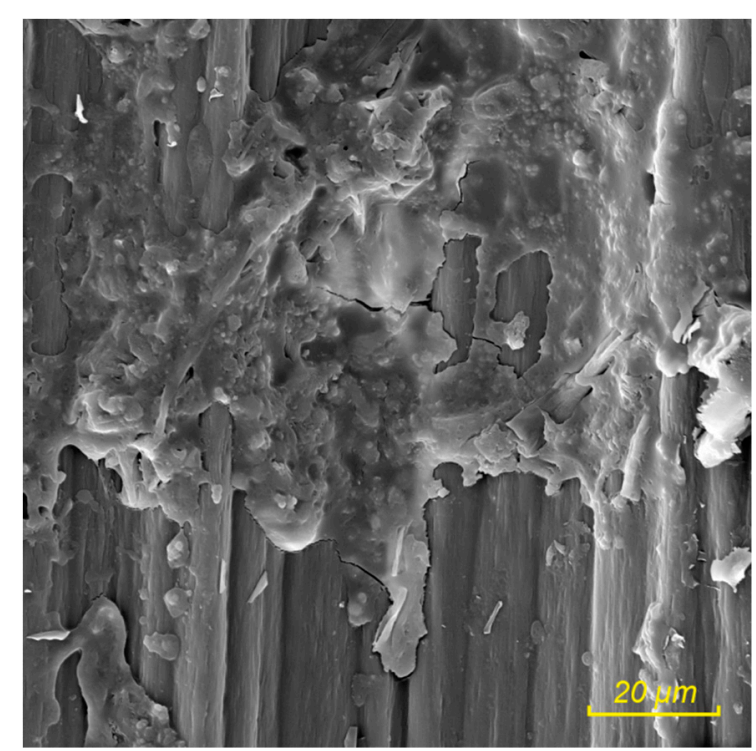

(b)

Figure 13. Particle board from wheat straw bonded with UF adhesive, plasma treated particles, weaker degree of treatment; (a) adhesion and cohesion failure, (b) dust particles in the adhesive.

\subsubsection{Particles Treated with a Higher Degree of Plasma Treatment}

The adhesive creates large surface layers torn in places due to mechanical tearing (Figure 14a), more often, however, it is possible to observe a smooth adhesive surface with an imprint of the torn-off material (Figure 14b). The captured damaged fragments of material were almost impossible to trace on the sample, and the adhesion was worse than in the previous weaker treatment variant. It is apparent that the higher power used in this plasma treatment has already exceeded the optimal degree of treatment [17].

Also, there is no apparent loss of epidermis in both plasma treatments, as can be seen when wet treatment is used [19]. 


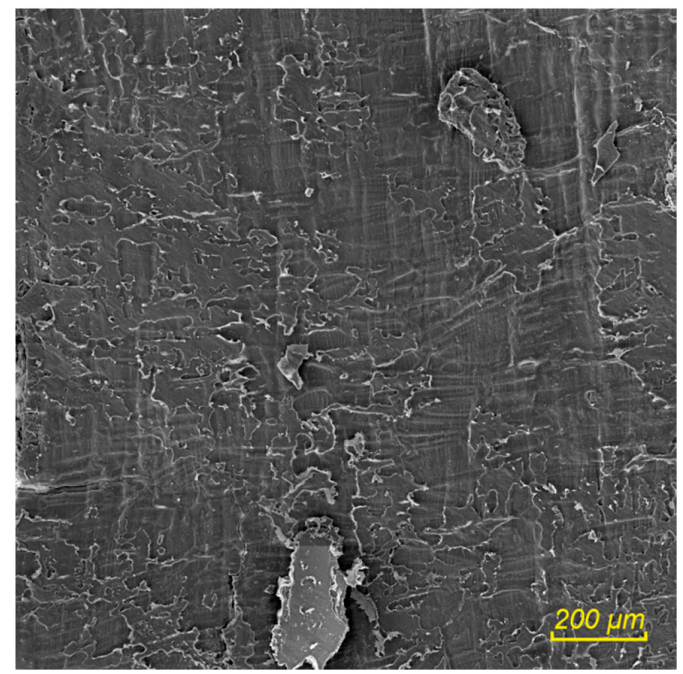

(a)

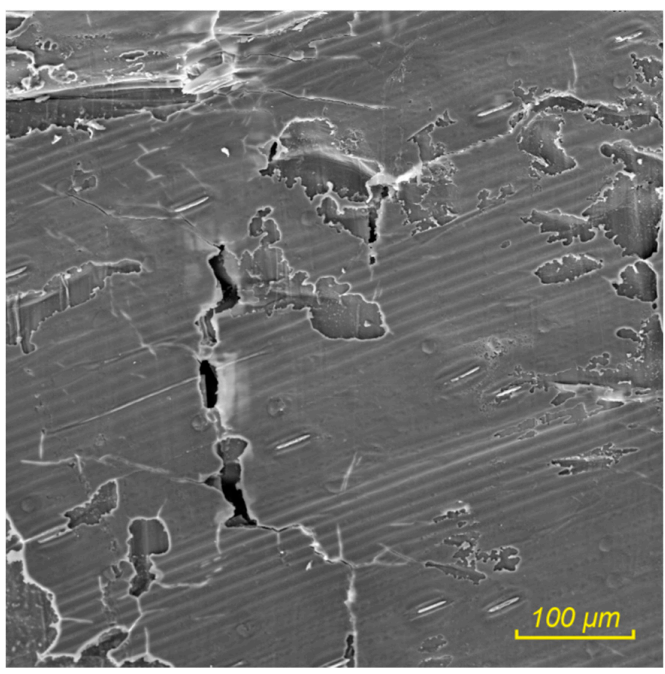

(b)

Figure 14. Particle board from wheat straw bonded with UF adhesive, plasma treated particles, higher degree of treatment; (a) adhesion and cohesion failure in the adhesive, (b) adhesion error.

\subsection{Composites from Treated Wheat Husks Bonded with UF Resin}

\subsubsection{Untreated Wheat Husks}

As in the case of the interaction of the UF adhesive and untreated wheat stalk particles, in the case of UF adhesive and wheat husks, the adhesion of the adhesive to the adherend surface is very weak. It creates adhesive drops on the surface of the material and does not spill, which indicates the lower surface energy of the husk surface than the used UF adhesive (Figure 15a) [11]. A frequent phenomenon are impurities of different sizes trapped in the adhesive (Figure 15b).

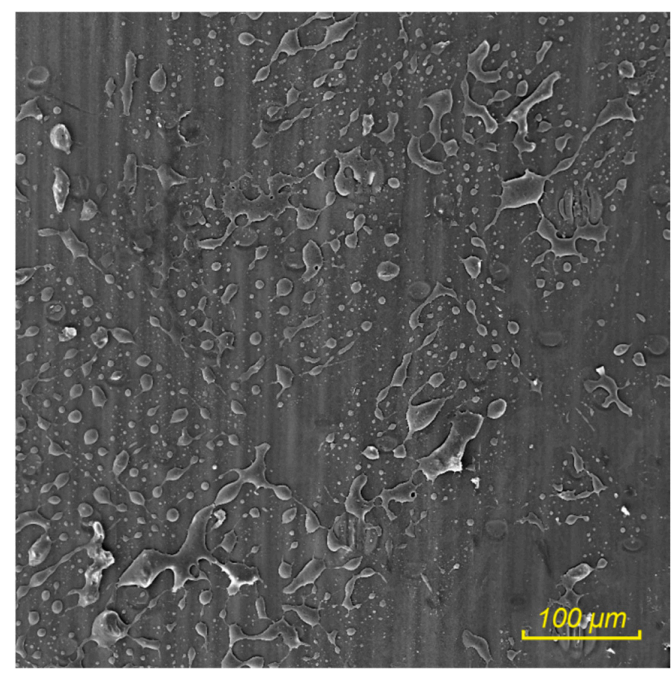

(a)

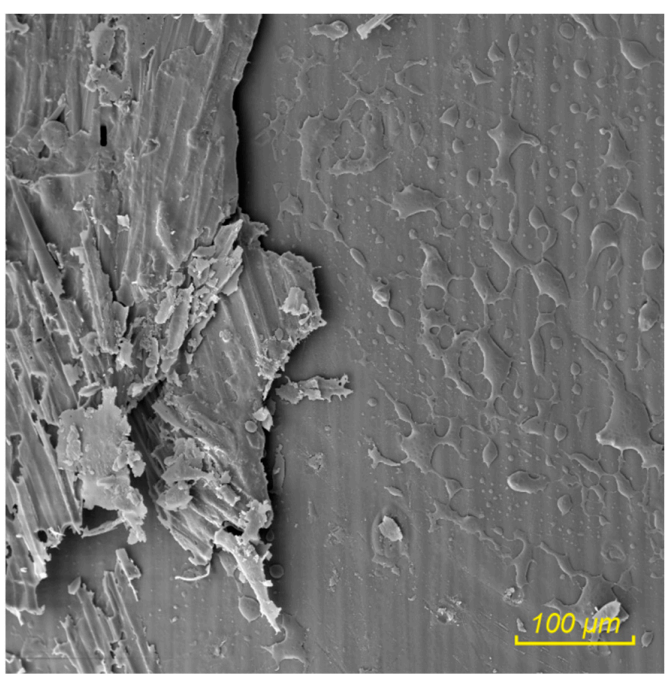

(b)

Figure 15. Particle board from wheat husks bonded with UF adhesive, untreated husks; (a) poor spilling of the adhesive, (b) impurities in the adhesive.

\subsubsection{Hydrothermally Treated Wheat Husks}

On the surface of hydrothermally treated husks, the UF adhesive showed both good wettability and drop formation (Figure 16). However, the created bond was the strongest of all other husk surface pre-treatment variants [11]. 


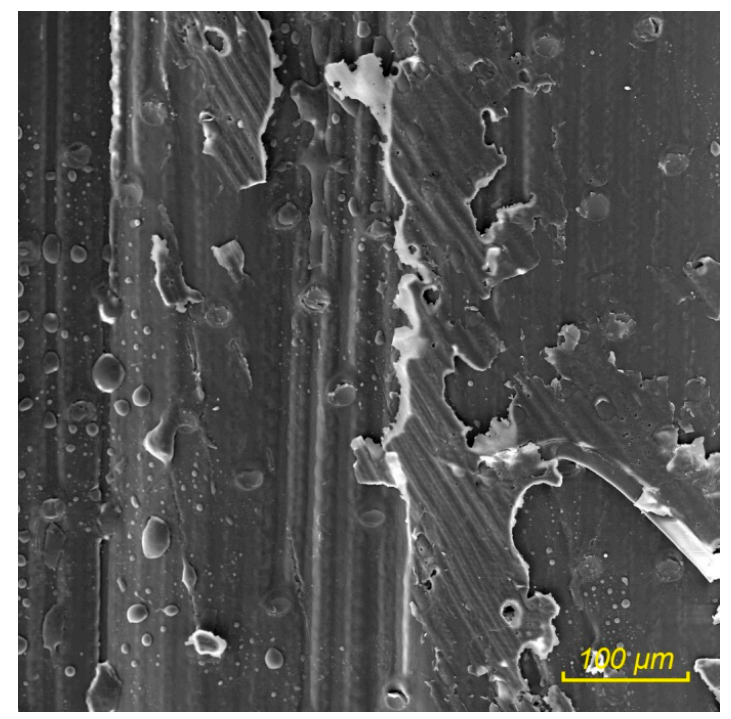

Figure 16. Particle board from wheat husks bonded with UF adhesive, hydrothermally treated husks; nature of the spilling of the adhesive on the surface of the husks.

\subsubsection{Chemically Treated Wheat Husks}

In this case, better wettability of the adhesive (Figure 17a) can be observed compared to the other samples in this group. As a result of impurities washing through the wet treatment, it was almost impossible to observe impurities on the husk surface. Furthermore, on the sample there were numerous areas with a particular crystalline structure-non-eluted $\mathrm{NaOH}$ residues (Figure 17b). This aggressive treatment, however, disrupted the husk structure, thereby reducing the overall strength of the composite [11]. Another effect of treatment by sodium hydroxide was presented by Tran et al. (2014) [20]. In this study authors assumed that wheat husks have a very thin film of lignin covering the surface, and this film can be dissolved using alkaline treatment, which may enhance the adhesion.

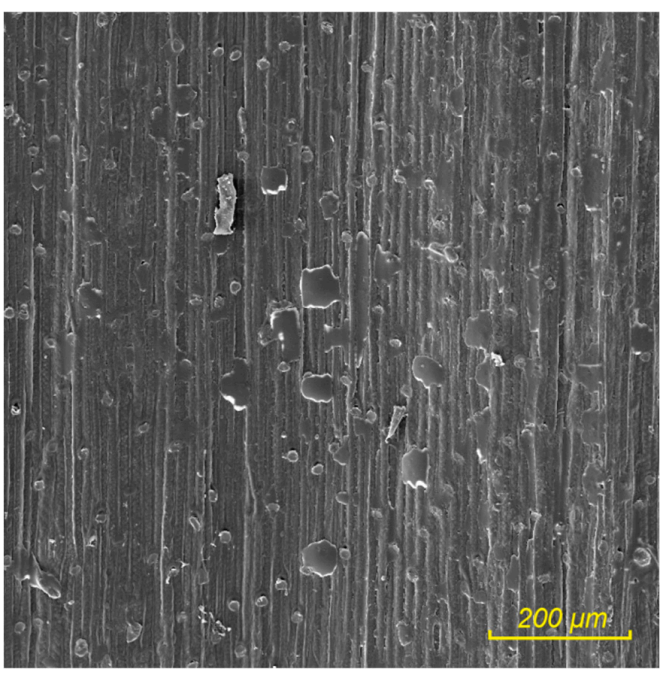

(a)

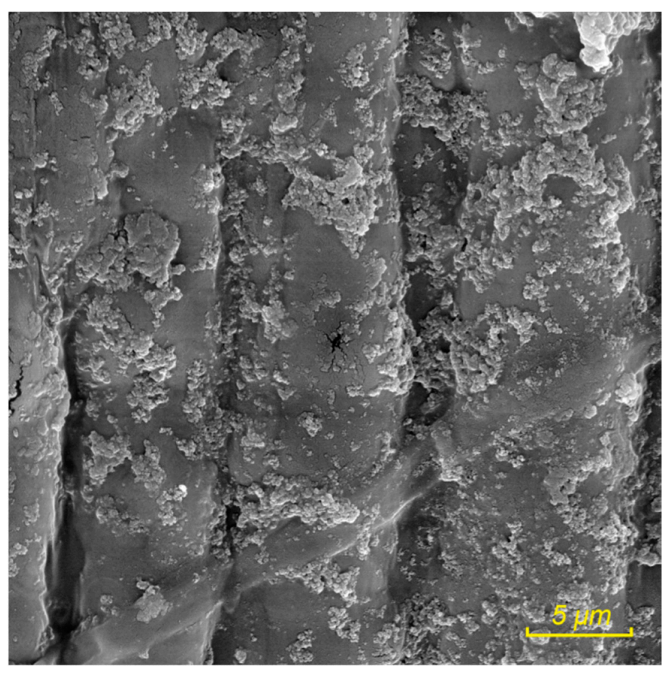

(b)

Figure 17. Particle board from wheat husks bonded with UF adhesive, alkaline treated husks; (a) dispersion of adhesive, (b) $\mathrm{NaOH}$ residues on the surface of husks.

\subsubsection{Plasma-Treated Wheat Husks}

This variant is very similar to the reference variant. However, the quantity of adhesive is greater on this sample and the wettability is slightly better (Figure 18a). The adhesive produces round-shaped 
or partially spilled drops. Larger peel layers with an impression of the torn-off material are often visible (Figure 18b). The disadvantage of the dry treatment is the higher incidence of impurities.

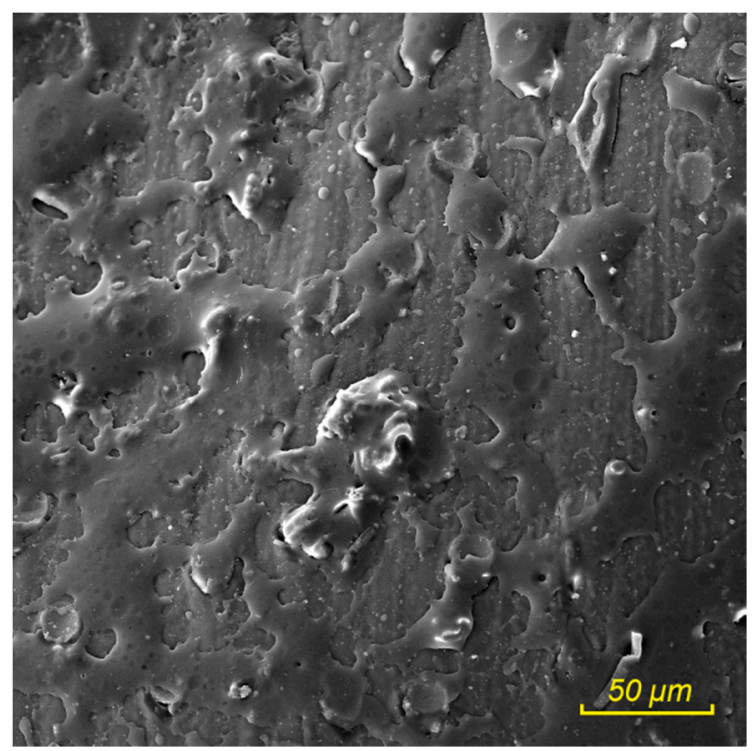

(a)

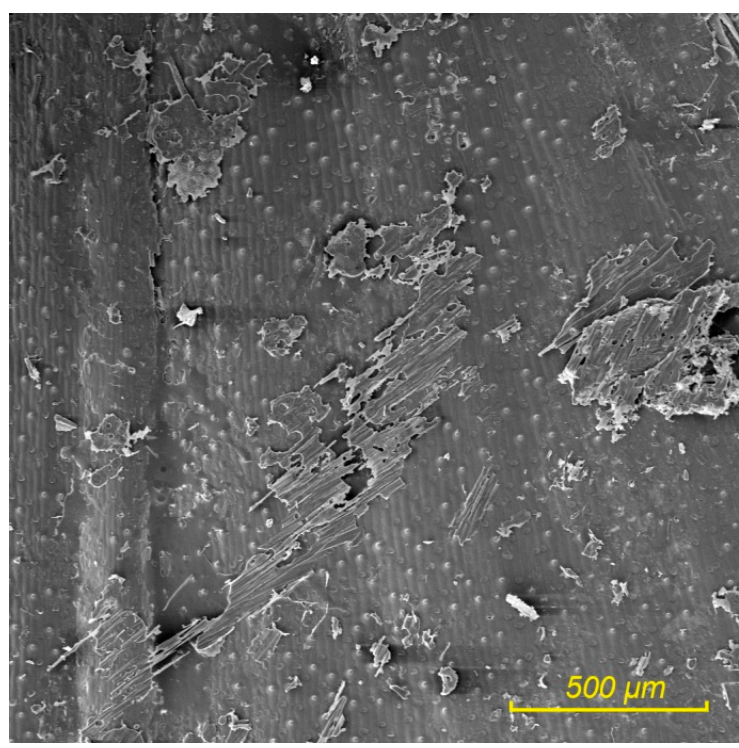

(b)

Figure 18. Particle board from wheat husks bonded with UF adhesive, plasma treated husks; (a) dispersion of adhesive, (b) nature of bond failure.

\subsection{Practical Implications of This Study}

Based on the results from the SEM analysis of bond rupture, particle surface morphology and adhesive dispersion, the following findings and recommendations can be made:

- The epoxy-polyester adhesive showed a better dispersion on the surface of the rapeseed particles than the urea-formaldehyde adhesive.

- The alkaline treatment significantly increased the adhesion of the adhesive to the surface.

- The hydrothermal treatment caused, among other things, a thorough washing of the surface from dust, which also had a significant positive effect on adhesion.

- The weakness of the joints examined was the pith tissue of the stalks. Removing it before gluing would certainly increase the mechanical properties of the composites.

- Thorough washing out after chemical treatments is necessary. The non-washed chemicals may further react with the adhesive.

- Enzyme treatment slightly improved adhesion, but not as much as expected.

- Dry plasma treatment did not wash the surface from dust, but it activated the surface well and improved adhesion. Important in this adjustment is the correct intensity setting. Intensity higher than optimal is counterproductive.

However, taking into account the results of tests of mechanical properties from previous studies, the alkaline treatment must be excluded from the suitable variants. This treatment was too aggressive, it disrupted the structure of the particles and husks and, therefore, the mechanical properties of the resulting composites decreased.

An essential condition for better adhesion is to reduce the surface energy of the particles below the surface energy level of the adhesive mixture.

\section{Conclusions}

The captured images of rapeseed particle board samples suggest that the most effective treatment was alkaline treatment. Compared to the others, it provided better spilling of the adhesive and its 
adhesion to the surface, and damage occurred quite often in the material. This treatment had the same effect on husks. Unfortunately, the chosen alkaline treatment was too aggressive and disrupted the structure of the treated particles and husks deeper in the material and thus reduced the strength of the resulting composites. Enzymatic treatment proved to be a promising treatment, where xylanases and pectinases were simultaneously acting. These enzymes selectively disrupted the particle surface and did not disrupt the cellulose. The plasma treatment slightly improved the adhesion of the adhesive to the substrate, but it is necessary to use an optimal degree of plasma treatment, one that is not overly high. In conclusion, suitable forms of pre-treatment material have been found to increase adhesion between the lignocellulosic material and the adhesive. However, their applicability in practice remains a question mainly because of additional cost. The hydrothermal, alkaline and enzymatic treatments are wet treatments that produced waste water in the production of particleboards.

Author Contributions: Conceptualization, Š.H.; Data curation, J.Č.; Formal analysis, M.L.; Investigation, J.Č.; Methodology, Š.H.; Supervision, Š.H.; Writing-original draft, Š.H. and J.Č.; Writing-review and editing, M.L.

Funding: This research was funded by the OP RDE, grant number CZ.02.1.01/0.0/0.0/16_019/0000803. The APC was funded by the Czech University of Life Sciences in Prague.

Acknowledgments: The authors are grateful for the support of "Advanced research supporting the forestry and wood-processing sector's adaptation to global change and the 4th industrial revolution", OP RDE (Grant No. CZ.02.1.01/0.0/0.0/16_019/0000803), and Project No. QK1920391 financed by the Ministry of Agriculture of the Czech Republic called "Diverzifikace vlivu biohospodářství na strategické dokumenty lesnicko-dřevařského sektoru jako podklad pro státní správu a návrh strategických cílů do roku 2030". (Diversification of the influence of bioeconomy on forestry-timber sector strategic documents as a basis for state administration and proposal of strategic goals by 2030.)

Conflicts of Interest: The authors declare no conflict of interest. The funders had no role in the design of the study; in the collection, analyses, or interpretation of data; in the writing of the manuscript; or in the decision to publish the results.

\section{References}

1. Maity, S.; Gon, D.P.; Paul, P.A. Review of Flax Nonwovens: Manufacturing, Properties, and Applications. J. Nat. Fibers 2014, 11, 365-390. [CrossRef]

2. Hýsek, Š.; Frydrych, M.; Herclík, M.; Louda, P.; Fridrichová, L.; Van, S.L.; Chi, H.L. Fire-Resistant Sandwich-Structured Composite Material Based on Alternative Materials and Its Physical and Mechanical Properties. Materials 2019, 12, 1432. [CrossRef] [PubMed]

3. Viel, M.; Collet, F.; Prétot, S.; Lanos, C. Hemp-Straw Composites: Gluing Study and Multi-Physical Characterizations. Materials 2019, 12, 1199. [CrossRef] [PubMed]

4. Wang, J.; Wang, B.; Liu, J.; Ni, L.; Li, J. Effect of Hot-Pressing Temperature on Characteristics of Straw-Based Binderless Fiberboards with Pulping Effluent. Materials 2019, 12, 922. [CrossRef] [PubMed]

5. Alcock, M.; Ahmed, S.; DuCharme, S.; Ulven, C.A. Influence of Stem Diameter on Fiber Diameter and the Mechanical Properties of Technical Flax Fibers from Linseed Flax. Fibers 2018, 6, 10. [CrossRef]

6. Crawford, B.; Pakpour, S.; Kazemian, N.; Klironomos, J.; Stoeffler, K.; Rho, D.; Denault, J.; Milani, A. Effect of Fungal Deterioration on Physical and Mechanical Properties of Hemp and Flax Natural Fiber Composites. Materials 2017, 10, 1252. [CrossRef] [PubMed]

7. Kremensas, A.; Kairytè, A.; Vaitkus, S.; Vejelis, S.; Balčiūnas, G. Mechanical Performance of Biodegradable Thermoplastic Polymer-Based Biocomposite Boards from Hemp Shivs and Corn Starch for the Building Industry. Materials 2019, 12, 845. [CrossRef] [PubMed]

8. Hýsek, ک̌.; Gaff, M.; Sikora, A.; Babiak, M. New composite material based on winter rapeseed and his elasticity properties as a function of selected factors. Compos. Part B Eng. 2018, 153, 108-116. [CrossRef]

9. Částková, T.; Hýsek, Š.; Sikora, A.; Schönfelder, O.; Böhm, M. Chemical and Physical Parameters of Different Modifications of Rape Straw (Brassica napus L.). BioResources 2018, 13, 104-114. [CrossRef]

10. Bekhta, P.; Korkut, S.; Hiziroglu, S. Effect of Pretreatment of Raw Material on Properties of Particleboard Panels Made from Wheat Straw. BioResources 2013, 8, 4766-4774. [CrossRef]

11. Hýsek, Š.; Podlena, M.; Bartsch, H.; Wenderdel, C.; Böhm, M. Effect of wheat husk surface pre-treatment on the properties of husk-based composite materials. Ind. Crops Prod. 2018, 125, 105-113. [CrossRef] 
12. Hýsek, ̌̌.; Sikora, A.; Schönfelder, O.; Böhm, M. Physical and Mechanical Properties of Boards Made from Modified Rapeseed Straw Particles. BioResources 2018, 13, 6396-6408.

13. Klímek, P.; Morávek, T.; Ráhel, J.; Stupavská, M.; Děcký, D.; Král, P.; Kúdela, J.; Wimmer, R. Utilization of air-plasma treated waste polyethylene terephthalate particles as a raw material for particleboard production. Compos. Part B Eng. 2016, 90, 188-194. [CrossRef]

14. Liu, Y.; Tao, Y.; Lv, X.; Zhang, Y.; Di, M. Study on the surface properties of wood/polyethylene composites treated under plasma. Appl. Surf. Sci. 2010, 257, 1112-1118. [CrossRef]

15. Zhang, L.; Hu, Y. Novel lignocellulosic hybrid particleboard composites made from rice straws and coir fibers. Mater. Des. 2014, 55, 19-26. [CrossRef]

16. Hýsková, P.; Hýsek, Š.; Schönfelder, O.; Šedivka, P.; Lexa, M.; Jarský, V. Utilization of Agricultural Rests: Straw-Based Composite Panels Made from Enzymatic Modified Wheat and Rapeseed Straw. Ind. Crops Prod. 2019. submitted.

17. Hýsek, Š.; Podlena, M.; Böhm, M.; Bartsch, H.; Wenderdel, C. Effect of Cold Plasma Surface Pre-treatment of Wheat Straw Particles on Straw Board Properties. BioResources 2018, 13, 5065-5079.

18. Sikora, A.; Gaff, M.; Hysek, Š.; Babiak, M. The plasticity of composite material based on winter rapeseed as a function of selected factors. Compos. Struct. 2018, 202, 783-792. [CrossRef]

19. Gajdačová, P.; Hýsek, Š.; Jarský, V. Utilisation of Winter Rapeseed in Wood-based Materials as a Solution of Wood Shortage and Forest Protection. BioResources 2018, 13, 2546-2561. [CrossRef]

20. Tran, T.P.T.; Bénézet, J.-C.; Bergeret, A. Rice and Einkorn wheat husks reinforced poly(lactic acid) (PLA) biocomposites: Effects of alkaline and silane surface treatments of husks. Ind. Crops Prod. 2014, 58, 111-124. [CrossRef]

(C) 2019 by the authors. Licensee MDPI, Basel, Switzerland. This article is an open access article distributed under the terms and conditions of the Creative Commons Attribution (CC BY) license (http://creativecommons.org/licenses/by/4.0/). 